\title{
A STUDY OF THE BODY WEIGHT IN ANOREXIA NERVOSA
}

\author{
By R. W. Emanuel, M.A., D.M., M.R.C.P. \\ Senior Medical Registrar, Middlesex Hospital
}

Loss of weight has always been accepted as one of the cardinal features in anorexia nervosa, but there has been no previous attempt to study its fluctuations in relation to the natural history of the disease.

The object of the work recorded here was to determine the following points:-

(a) The weight of patients before the development of anorexia nervosa.

(b) The maximum amount of weight lost in non-fatal cases in relation to the duration of the disease.

(c) The amount of weight lost in fatal cases in relation to the duration of the disease.

(d) The weight of patients some years after the return of normal menstruation.

(e) The weight of patients when regular menstruation returned.

Owing to the comparative rarity of the disease too few cases could be observed personally to obtain significant results; therefore all cases from the literature have been included where sufficient data pertinent to this survey had been recorded.

\section{The Criteria for the Clinical Diagnosis of Anorexia Nervosa}

The criteria that were required before the diagnosis of anorexia nervosa was accepted were as follows : Anorexia or failure to eat, loss of weight, amenorrhoea or oligomenorrhoea.

All cases with active organic disease were excluded as were patients suffering from a psychosis, for although anorexia, loss of weight and frequently amenorrhoea occurred with mental disease, it was considered that these symptoms were secondary to the mental disturbance.

Difficulty was experienced in finding definite criteria by which the duration of the disease could be estimated. For the purpose of this study the duration of the illness was measured by the period of the amenorrhoea (Gee, 1907). This excluded males from certain observations; but as women form over 90 per cent. of all cases, it was thought that this omission would be of little significance.
Twenty-four cases of anorexia nervosa were collected from the records of the Middlesex Hospital.. All living cases were seen and examined personally. In ro of these cases the disease was still present, "symptoms. having persisted from 5 to 25 years. 'A further 9 patients had recovered as judged by the return of normal menstruation. These cases had been followed for periods varying from I to 13 years after recovery. The remaining 5 cases had died.

\section{Standards Used}

Standard weights have been obtained from Kemsley's (1952) paper which gave the mean weights of a British population classified according to age, sex and height. Although these figures differed slightly from the American standards the percentage error was small particularly for women under the age of 30 .' Kemsley's standards have been applied therefore to all cases.

Throughout this work the patient's height was recorded in inches, the weight in pounds and the duration of the disease in years. All heights include $I \frac{1}{2}$ inches for shoes and all weights 6 pounds for light clothing. In reported cases, unless otherwise stated, it was assumed that patients were weighed in light clothes and measured in shoes.

\section{Results}

(a) The weight of patients before the development of anorexia nervosa

In the present series the weight was known before the onset of symptoms in 20 cases. A further 86 cases were collected from the literature making a total of 106 cases. Fig. I shows that 65 of these were above and 41 normal or below their standard weight before the onset of symptoms. The mean weight was 104.6 per cent. of the standard. This mean is significantly higher than that of the corresponding standards $(t=3.37$; $p$ lies between .or and .001).

Eighty-seven of these 106 cases (82 per cent.) developed symptoms between the ages of $\mathrm{I}_{5}$ and 25 years (Fig. 2). 


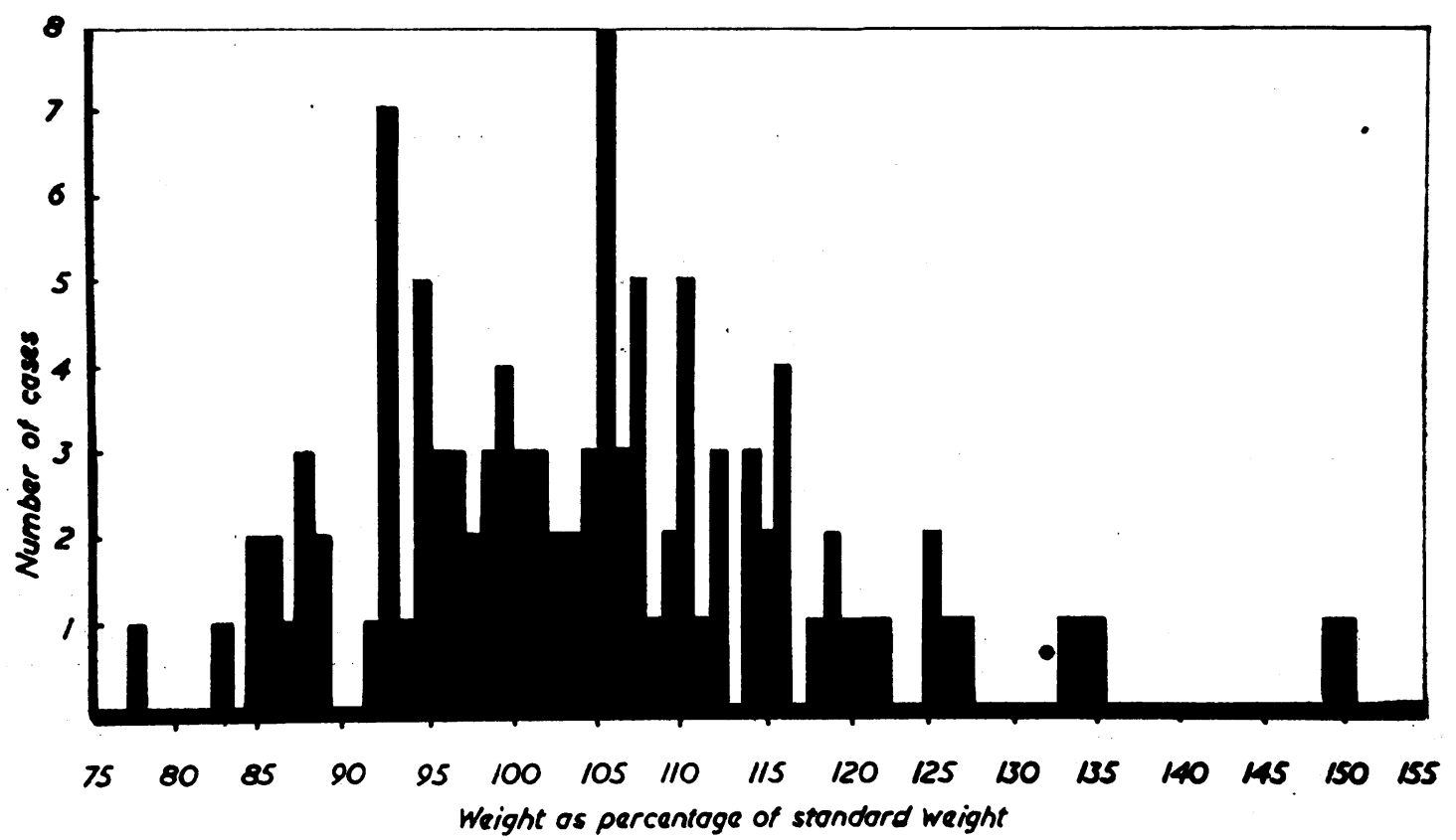

Fig. I.-The weight in 106 cases of anorexia nervosa before the onset of symptoms.

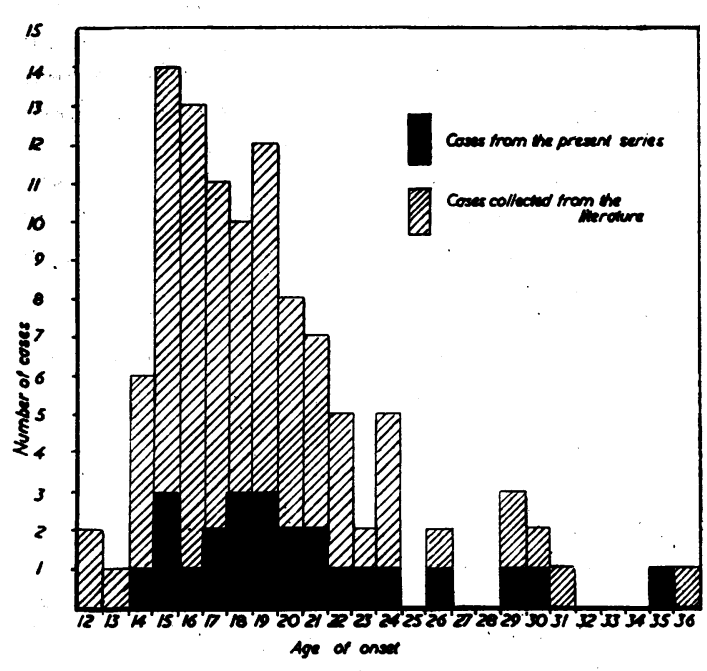

FIG. 2.-The age of onset in 106 cases of anorexia nervosa.

(b) The maximum amount of weight lost in non-fatal cases in relation to the duration of the disease

It seemed improbable that there would be any simple relationship between the maximum amount of weight lost and the duration of the disease, for in long standing cases it is known that patients may remain for many years in a state of severe undernutrition without apparent change.

The effects of various treatment on the duration of anorexia nervosa has not been studied owigg to the small number of cases available and diversity of treatments used but, with the exce tion of leucotomy, the duration appeared to uninfluenced by any form of therapy, recovery often occurring after treatment had beeno abandoned.

In the present series the duration of amenorrhoea in the 9 cases which recovered varied between months and $10 \frac{1}{2}$ years, exceeding $3 \frac{1}{2}$ years in 5 of them. The average duration was 4 years months. In a review of the literature, only $1 \%$ cases were found in which the follow-up had been of sufficient length to determine the total period:of the amenorrhoea. In 18 of these, the period $B$. varied from 6 months to $3 \frac{1}{2}$ years, the average duration of the 19 cases being 2 years 9 months.

Considering these 28 cases ( 9 from the presen series and I9 from the literature) the average $>$ duration of the disease was 3 years 4 months. It is: certain, however, that this does not reflect the true duration of anorexia nervosa as so few cases of long duration have been included. These chronic cases are not uncommon but have not been followed up for sufficiently long to determine their full duration.

In Fig. 3, the maximum amount of weight lost expressed as a percentage of the standard weight; is plotted against the duration of the disease as: measured by the period of the amenorrhoea. It is 


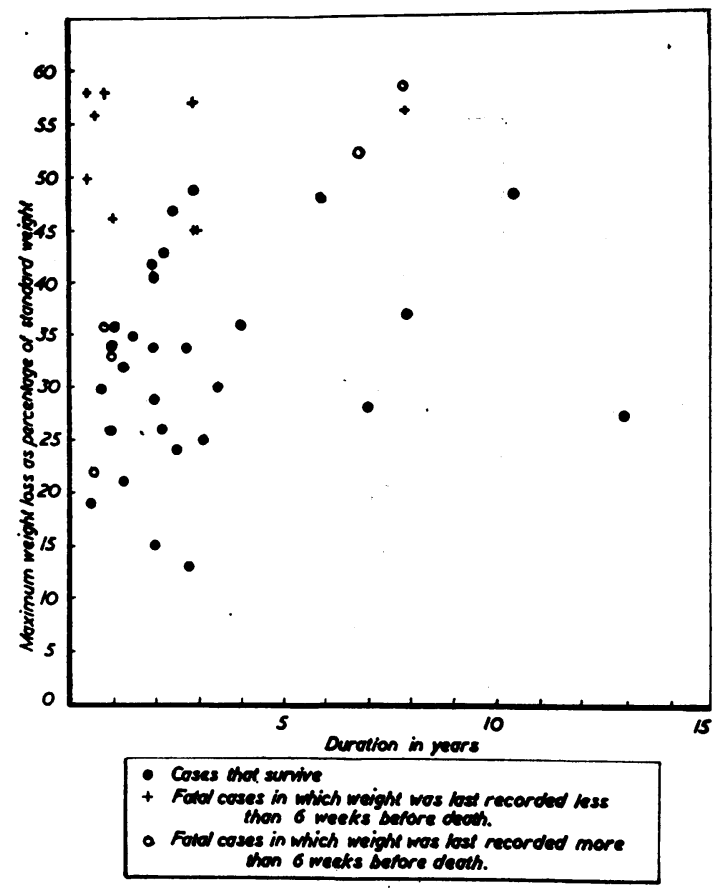

FIG. 3.-The relation between the maximum amount of weight lost and the duration of the disease in 42 cases of anorexia nervosa (comprising 28 non-fatal cases Section b, and 14 fatal cases Section c).

apparent that there is no simple relationship between these variables in anorexia nervosa.

(c) The amount of weight lost in fatal cases in relation to the duration of the disease

The possibility of a fatal outcome in anorexia nervosa was known to the early writers, Morton (1694), Gull (1874) and Fenwick (1880). Only a few fatal cases, however, are sufficiently fully documented to determine the relation between the duration of the disease and the amount of weight lost.

Any case where the history suggested or the post mortem proved active tuberculosis has been excluded, because such an infection masks the normal course of the disease, particularly the terminal stages (Whytt, I768; Osgood, 1938; Brosin and Apfelbach, 194I).

A total of 14 fatal cases were studied. In 9 of these, post mortem examinations were obtained and no significant organic disease found. In the present series there were 3 fatal cases uncomplicated by tuberculosis and a further II were obtained from the literature. In all, the duration of the disease was known and the weight had been recorded at or shortly before death. In 5 cases, however, the final weight was recorded more than 6 weeks before death. It was described in such terms as 'some little time before death'. These cases are marked in Fig. 3 .

In the 9 cases in which the weight of the patient is known within 6 weeks of death, the weight varied from 42 to 55 per cent. of the standard. This great loss of weight, however, is not necessarily fatal. One case of the present series was only 40 per cent. of her standard but is still living 12 years later. Similar cases are recorded in the literature. The outcome of the disease may be related, however, to the rate at which the weight is lost. In the 14 fatal cases the duration of the disease varied from 1 month to 8 years but was 3 years or less in ro of them. From Fig. 3 it will be seen that the fatal cases not only lose more, weight than the average case that survives, but they do so more rapidly.

The mean percentage loss of weight is significantly greater in the fatal than the non-fatal cases $(t=4.68 ; p$ is less than 0.001$)$ and if the rate of weight loss is compared in fatal and non-fatal cases it is found to be significantly greater in fatal cases $(t=3.79 ; p$ is less than 0.001$)$.

In many of the 42 cases shown in Fig. 3 the weight before the development of anorexia nervosa was unknown. It was therefore assumed that patients were of standard weight before the onset of symptoms. This assumption was based on the fact that the mean weight of 106 cases before the disease developed was ro4.6 per cent. of the standard (Section a). Consequently the difference between the maximum weight loss expressed as a percentage of the standard and expressed as a percentage of the patient's actual weight will be slight. This difference has been ignored in Fig. 3 as the object here was to compare 2 groups of cases, those that were fatal and those that survived.

\section{(d) The weight of patients some years after the return of normal menstruation}

Ryle (1936) said that some cases remained underweight without being wasted and carried on a tolerably normal existence. $\mathrm{He}$ did not state, however, whether normal menstrual activity had returned. It was therefore decided to survey the weights of patients a varying number of years after the return of normal menstruation and to determine whether or not their weight differed significantly from normal.

Seventeen cases were studied, 9 from the present series and 8 from the literature. The former were followed up for I to 13 years and the latter 6 months to 4 years after the return of normal menstruation.

In 5 of these 17 cases (29 per cent.), the weight had never returned to normal since the onset of the disease. The maximum weight recorded in 


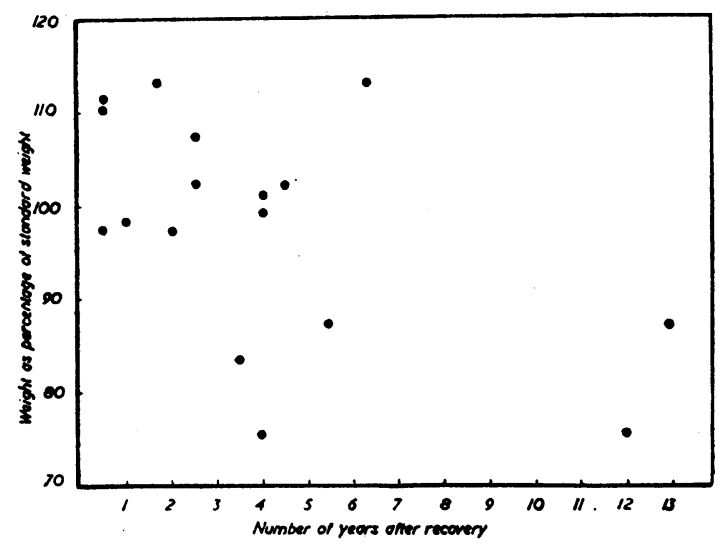

FIG. 4.-The weight of 17 cases of anorexia nervosa a varying number of years after recovery.

these patients after the return of menstruation varied from 76 to 88 per cent. of the standard, although all had been above 92 per cent. of their standard weight before the onset of anorexia nervosa. In the remaining 12 cases the patient's weight had returned to normal and varied between 98 and 114 per cent. of the standard.

Fig. 4 shows there is no relationship between these weights expressed as a percentage of the standard and the number of years after recovery.

The mean weight for the whole group is not significantly different from the mean of the corresponding standards $(t=0.590 ; p$ lies between 0.5 and 0.6 ).

\section{(e) The weight of patients when regular menstruation returned}

Throughout this study it has been assumed that the return of normal menstruation indicated a patient's physical recovery from anorexia nervosa. If this is so, then the weight should also be normal when the menses return. Decourt (1946) and Decourt and Michard (1949) have already pointed out that in a proportion of cases the return of normal menses occurred sometimes before and sometimes: after the weight returned to normal. No authoritative statement could be found on the relationship of the body weight to the standard at the time when the periods return.

In the present series, the weight was known in 9 cases at the time the periods returned to normal. A further 12 cases were added from the literature. In these 21 cases, represented graphically in Fig. 5 , the weight varied from 78 to 120 per cent. of the standard when the periods returned to normal. The mean weight at this time was 9I per cent., but in only 5 cases was the weight over 100 per cent. when normal menstruation returned.

The mean weight for the whole group is

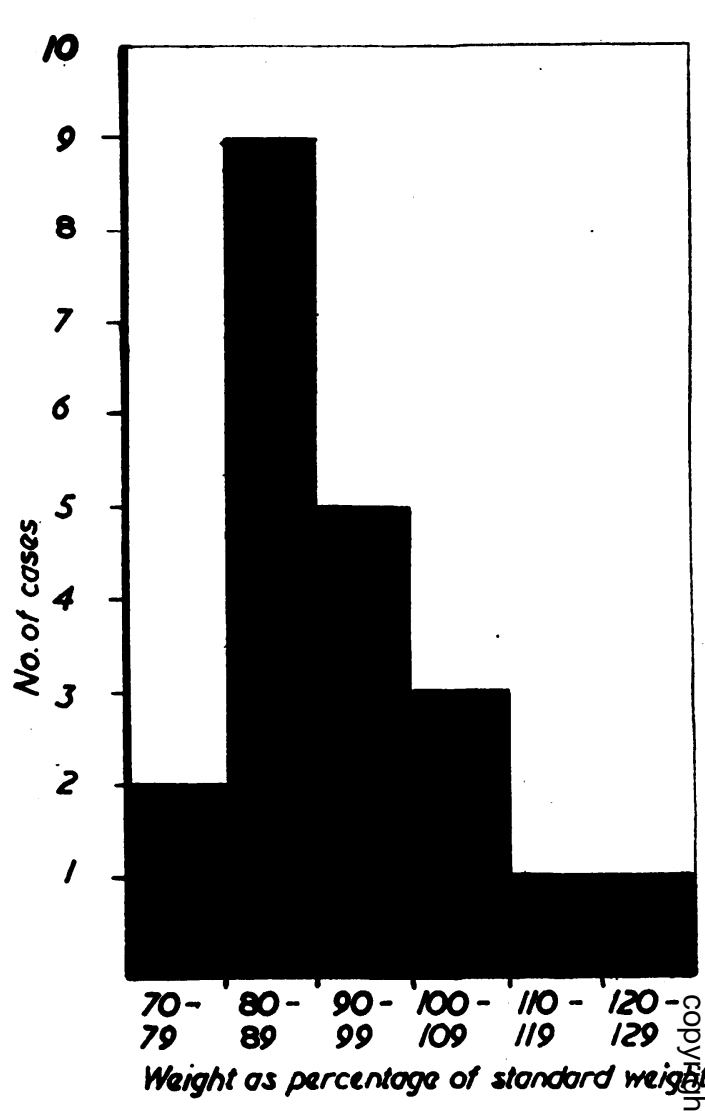

FIG. 5.-The weight of 2 I cases of anorexia nervosa when normal menstruation returned.

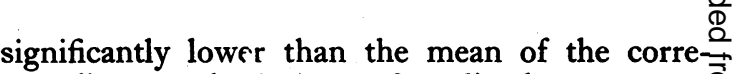
sponding standards $(t=2.98 ; p$ lies between 0.013 and 0.001 ). It appears therefore that the menses, generally return to normal before the patients have regained their standard weight.

\section{Discussion}

From an analysis of these facts certain observa tions can be made on the body weight in patients suffering from anorexia nervosa.

Many of the patients who develop the disease are overweight before the onset of symptoms. This finding may in part be explained by the fact that anorexia nervosa usually develops during ado lescence, a time when obesity is common. Further more, obesity at this age often embarrasses the patient and so leads to voluntary restriction of diet which in a certain proportion of unstable people initiates the process of anorexia nervosa. Sheldob (1937) suggested that in some cases obesity waई due to anterior pituitary deficiency while in other\& this deficiency was manifest by a delay in theo onset of puberty and subnormal height. The 
latter points, however, could not be confirmed. Puberty occurred before the age of $14 \frac{1}{2}$ years in 9I per cent. of the present series and the mean height of the ror females who developed anorexia nervosa was 63.80 inches (S.D. 3.07), which did not differ significantly from the mean of the standard heights, which was 6r.92 inches (S.D. 2.58) (Kemsley 1952). The cause of obesity during adolescence may well be an imbalance of the endocrine function. At the same time there does not appear to be sufficient evidence that anterior pituitary deficiency is an aetiological factor in anorexia nervosa, although it is probable that hypofunction of the anterior pituitary occurs soon after the disease is established. The clinical manifestation of this is the early appearance of amenorrhoea in the majority of cases.

When the duration of the disease is known, it appears that there is a significant difference in the rate of weight loss in fatal and non-fatal cases. From the figures available, the non-fatal cases lose weight at the rate of 1.25 per cent. of their body weight per month, in contrast to the fatal cases which lose 3.5 per cent. of their body weight per month. The rate of weight loss, however, is inconstant, except possibly in the early stages of the disease. This is true particularly in the nonfatal cases of long duration, where the rate of weight loss diminishes or even ceases after a varying period of time. This is one of the factors which accounts for the lack of a simple relationship between the duration of the disease and the maximum amount of weight lost. There is no doubt, however, that cases which lose weight rapidly in the early stages often die, but how this rate of weight loss compares with that in non-fatal cases over the same period of the disease is still to be determined.

Throughout this work the return of normal menstruation has been taken to signify the end of the disease. From the available figures it appears that the weight of patients at this time is significantly lower than normal. Amenorrhoea therefore, is not only an early symptom in the majority of cases but the return of normal menstruation is an early sign of recovery, often occurring before the patient has regained her standard weight. If any error has been incurred by taking return of men- struation to denote the patient's return to normality, it is probably only slight, tending to underestimate the duration of the disease.

In common with the findings of other writers (Ryle 1936), a proportion of cases remained underweight for a varying number of years after the periods had returned to normal. It might be thought that these would be more prone to relapse than those of normal weight, but in the 5 cases studied there was no evidence of this.

\section{Conclusions}

I. Patients who develop anorexia nervosa are frequently overweight before the onset of symptoms.

2. There is no direct relationship between the duration of the disease and the maximum amount of weight lost.

3. Fatal cases lose more weight and do so more rapidly than those that survive.

4. Patients are frequently below their standard weight when the periods return to normal.

5. The patient's weight a varying number of years after recovery from anorexia nervosa does not differ significantly from normal.

\section{Acknowledgments}

I am grateful to the physicians of the Middlesex Hospital for allowing me to study their cases.

This work formed part of a thesis accepted for the degree of D.M. at the University of Oxford.

\section{BIBLIOGRAPHY}

BROSIN, H. W., and APFELBACH, C. (194I), F. clin. Endocrin., I, 272.

DECOURT, J. (1946), Paris med., 36, 249.

DECOURT, J., and MICHARD, J. (1949), Sem. Hop. Paris, 25, 3343.

FENWICK, S. (1880), ' On Atrophy of the Stomach and on the Nervous Affections of the Digestive Organs,' p. 98 , London,
J. A. Churchill.

GEE, S. (1907), 'Medical Lectures and Aphorisms,' and ed., Ch. 6, London, Hodder and Stoughton.

GULL, W. W. (1874), Trans. clin. Soc. Lond., 7, 22.

KEMSLEY, W. F. F. (1952), Ann. Eugen., Lond., 16, 316.

MORTON, R. (1694), "Phthisiologia, or a Treatise of Consumptions,' p. 4, London, S. Smith and B. Walford.

OSGOOD, E. E. (1938), Endocrinology, 23, 656.

RYLE, J. A. (1936), Lancet, ii, 893.

SHELDON, J. H. (1937), Lancet, 'i, 369.

WHYTT, R. (1768), 'The Works of Robert Whytt,' p. 598, Edinburgh, T. Becket and P. A. De Hondt.

Details of the cases quoted from the literature may be found in the author's D.M. thesis (Oxford, 1954).

Bibliography continued from page 59-David Annis, Ch.M., F.R.C.S.Eng.

COUVELAIIE, R., (1951), Y. Urol. med., $57,530^{\circ}$

GILCHRIST, R. K., MERRICKS, J. W., HAMLIN, H. H., and RIEGER, I. T. (1950), S.G.O., 90, 752.

GREGOIR, W., and VAN WIEN, A.' (1955), Acta. Urol. Belg.,

JACOBBS, 72 ., ar d STIRLING, W. B. (1952), Brit. F. Urol, 24, 259. KINMAN, F. M., SAUER, D., HOUSTON, V. T., and MELICK, W. F. (1953), Arch. Surg., 66, 531.

KROENIG, (1907), Zbl. Gynak., 31, 559 .
LEVITSKY, V. (1953), Amer. F. Surg., 85, 91.

LOWSLEY'O. S., and'JOHNSON, T. H. (1955), f. Urol., 73, 83.

MOORE, T. (i953), Lancet, $i, 1176$.

PYRAH, L. N., and RAPER, F. P. (1955), Brit. F. Surg., 42, 337.

PYRAH, L. N. (1954), Ann. roy. Coll. Surg. Engl., 14 , 169.

SCHEELE, K. (1923), Beitr. z. Klin. Chir., 129, 414.

TASKER, J. H. (1953), Brit. F. Urol., 25, 349.

VERHOOGEN, J. (1908), Ass. Franc. d'Urol., 12, 362. 